\title{
Relação entre atividade de plasmina e frações de caseína durante 0 armazenamento do leite longa vida
}

Relationship between plasmin activity and casein fractions during storage of UHT milk

\section{Autores | Authors}

Carlos Humberto CORASSIN Roice Eliana ROSIM Estela KOBASHIGAWA

Universidade de São Paulo (USP)

Faculdade de Zootecnia e Engenharia de Alimentos

Departamento Engenharia de Alimentos Pirassununga/SP - Brasil e-mail: carloscorassin@usp.br roice@usp.br ekoba@usp.br

\section{Andrezza Maria FERNANDES}

Universidade de São Paulo (USP)

Faculdade de Zootecnia e Engenharia de Alimentos

Departamento de Ciências Básicas Pirassununga/SP - Brasil e-mail: andrezzaf@usp.br

\section{$\varangle$ Carlos Augusto Fernandes de} OLIVEIRA

Universidade de São Paulo (USP)

Faculdade de Zootecnia e Engenharia de Alimentos Departamento de Engenharia de Alimentos Av. Duque de Caxias Norte, 225

CEP: 13635-900

Pirassununga/SP - Brasil e-mail: carlosaf@usp.br

$\triangle$ Autor Correspondente / Corresponding Author

Recebido / Received: 07/06/2011

Aprovado / Approved: 29/01/2013

Publicado / Published: mar./2013

\section{Resumo}

Este estudo teve como objetivo correlacionar a atividade da plasmina e as concentrações de frações de caseína no leite longa vida (UAT) produzido em usina de beneficiamento do Estado de São Paulo. O leite cru foi submetido à pasteurização $\left(72-76^{\circ} \mathrm{C}, 15-20\right.$ segundos), seguida da esterilização por processo de injeção direta de vapor $\left(132-136{ }^{\circ} \mathrm{C}, 34\right.$ segundos), sendo homogeneizado e envasado assepticamente em embalagens cartonadas. Quatro lotes de UAT foram analisados para atividade de plasmina e frações de caseína após 10, 30, 60, 90 e 120 dias de armazenamento. A atividade de plasmina no leite longa vida aumentou durante o armazenamento, correlacionando-se negativamente com a concentração de $\alpha_{s 1}$-caseína. A atividade da plasmina apresenta resistência à esterilização do leite pelo processo UAT e aumenta a proteólise do leite longa vida como consequência da degradação da $\alpha_{\mathrm{s} 1}$-caseína.

Palavras-chave: Plasmina; Caseínas; Leite longa vida; Proteólise.

\section{Summary}

The objective of this study was to correlate the plasmin activity and the concentrations of casein fractions in ultra-high-temperature (UHT) milk manufactured in a dairy plant in the State of Sao Paulo, Brazil. Raw milk was pasteurized $\left(72-76{ }^{\circ} \mathrm{C}, 15-20\right.$ seconds), followed by direct steam injection into the milk (132-136 ${ }^{\circ} \mathrm{C}, 34$ seconds), then homogenized and aseptically packaged into cartons. Four replicates of the UHT milk were analyzed for the plasmin activity and casein fractions after 10,30,60, 90 and 120 days of storage. Plasmin activity significantly increased in the UHT milk during storage and was negatively correlated with the concentration of $\alpha_{\mathrm{s} 1}$-casein. Plasmin is resistant to milk sterilization by the UHT process, and increases proteolysis of the UHT milk as a consequence of $\alpha_{\mathrm{s} 1}$-casein degradation.

Key words: Plasmin; Caseins; UHT milk; Proteolysis. 


\section{Introdução}

A plasmina é uma enzima endógena do leite classificada como uma proteinase alcalina, análoga à enzima sérica do soro sanguíneo bovino; encontra-se associada às frações de caseína no leite, sendo responsável por aproximadamente $90 \%$ da proteólise total que ocorre no leite (FERNANDES e OLIVEIRA, 2007). A plasmina degrada $\beta$-, $\alpha_{S 1}$ - e $\alpha_{S 2}$-caseína, sendo que esta atividade proteolítica é maior em leites provenientes de vacas com mastites, em função do aumento na contagem de células somáticas (CCS) no leite (BASTIAN e BROWN, 1996). Diferentemente da plasmina, as proteases produzidas por microrganismos psicrotróficos no leite causam proteólise com maior intensidade nas frações $\beta$ - e $\kappa^{-}$, seguidas da $\alpha_{S 1}$-caseína (ISMAIL e NIELSEN, 2010; FERNANDES et al., 2008).

A plasmina compõe um sistema complexo, que inclui o plasminogênio, os ativadores de plasminogênio, os inibidores dos ativadores do plasminogênio e os inibidores da plasmina (FERNANDES et al., 2008). Verdi e Barbano (1991) demonstraram que as células somáticas no leite apresentam a capacidade de conversão de plasminogênio em plasmina, resultando em proteólise da caseína, o que confirma a associação entre a alta CCS e o aumento da atividade proteolítica da plasmina. No entanto, os componentes do sistema plasmina interagem entre si (BASTIAN e BROWN, 1996) e com outros componentes do leite, como a caseína (METWALLI et al., 1998) e as proteínas do soro (ISMAIL e NIELSEN, 2010; SAINT-DENIS et al., 2001), promovendo ou inibindo a proteólise, dependendo da intensidade do tratamento térmico e das condições de armazenagem do leite.

O leite longa vida se destaca por ser um produto de prateleira estendida, o que proporciona comodidade ao consumidor, principalmente em grandes centros urbanos. As vendas deste tipo de leite no Brasil representam $74 \%$ do volume total de leite fluido comercializado no país (ABLV, 2009). Considerando-se a importância econômica do leite longa vida no mercado e na dieta da população brasileira, existem poucos dados na literatura sobre os fatores que afetam a qualidade do produto nessas condições. Um dos principais problemas que afetam a qualidade do leite longa vida durante o armazenamento é a precipitação indesejável, ou a gelificação, ocasionando uma redução na sua vida útil. A ação proteolítica da plasmina sobre as frações de caseína do leite tem sido sugerida como um dos fatores causais da gelificação do leite longa vida durante o armazenamento (FERNANDES et al., 2008), tendo em vista que a plasmina é uma enzima termoestável, capaz de sobreviver à pasteurização e ao tratamento por esterilização do leite (KOHLMANN et al., 1988). O objetivo do presente trabalho foi verificar a relação entre a atividade de plasmina e as concentrações das frações de caseína no leite longa vida integral durante 120 dias de armazenamento.

\section{Material e métodos}

\subsection{Caracterização do leite cru usado na fabricação do leite longa vida}

O leite longa vida utilizado no experimento foi produzido em usina de beneficiamento localizada no município de Casa Branca-SP, utilizando-se lotes de leite cru recolhido em propriedades leiteiras associadas à indústria e entregue na usina em caminhões isotérmicos. Antes do início de cada lote de leite ser processado (8.000-15.000 L/lote), foram colhidas amostras em duplicata de $600 \mathrm{~mL}$ do leite cru armazenado no tanquesilo, para realização da contagem de células somáticas (CCS) por meio de contador eletrônico (Bentley, Chaska, Minnesota, USA), determinação da atividade de plasmina (SAINT-DENIS et al., 2001) e contagem de microrganismos mesófilos e psicrotróficos (APHA, 2004). Cada amostra foi composta por dez subamostras de $60 \mathrm{~mL}$ de leite, coletadas em intervalos de cerca de 10 minutos, durante a transferência do leite do tanque-silo para o tanque de equilíbrio do pasteurizador. Consideraram-se, como critério de inclusão no estudo, quatro lotes de leite cru cujas duplicatas analisadas apresentaram até $1,0 \times 10^{4}$ unidades formadoras de colônias (UFC) $\mathrm{mL}^{-1}$ para mesófilos e 1,0 × $10^{3}$ UFC $\mathrm{mL}^{-1}$ para psicrotróficos (LÜCK, 1987).

\subsection{Fabricação do leite longa vida}

O leite cru foi submetido à pasteurização rápida (HT-ST) em trocadores de calor a placas, sendo pré-aquecido a $50^{\circ} \mathrm{C}$, clarificado em centrífuga, aquecido a $72-75^{\circ} \mathrm{C}$ por $15-20$ segundos, imediatamente resfriado a $4{ }^{\circ} \mathrm{C}$ e estocado temporariamente em balão isotérmico, até o início do processamento para obtenção do leite longa vida. Em seguida, o leite tratado resfriado foi previamente aquecido a $85^{\circ} \mathrm{C}$ em trocadores tubulares, seguindo posteriormente na linha para injeção de vapor superaquecido, até atingir a temperatura de $132-135^{\circ} \mathrm{C}$, por 2-8 segundos. Na sequência do processo, o leite foi submetido à evaporação em câmara de vácuo parcial (-0,6 MPa), na qual sofreu um primeiro resfriamento até cerca de $70^{\circ} \mathrm{C}$, e à passagem em homogeneizadora de dois estágios (22-25 MPa), retornando ao trocador tubular para um segundo resfriamento à temperatura de cerca de $20{ }^{\circ} \mathrm{C}$. O produto foi envasado automaticamente em embalagens assépticas cartonadas de $1 \mathrm{~L}$, em sistema de torre $\left(\right.$ TetraPak $\left.^{\circledR}\right)$. Todas as unidades produzidas em cada lote ficaram retidas na usina até o término do período de observação de amostras do lote, mantidas em estufa a $35^{\circ} \mathrm{C}$ por sete dias. Após a liberação de cada lote pela empresa, foram reservadas dez unidades do produto para 
fins de análises laboratoriais, as quais foram armazenadas à temperatura ambiente $\left(22-27^{\circ} \mathrm{C}\right)$ durante 120 dias. As análises foram efetuadas nos quatro lotes de leite longa vida, aos 10, 30, 60, 90 e 120 dias após a fabricação.

\subsection{Determinação da atividade de plasmina}

A atividade da plasmina no leite longa vida foi determinada por meio da metodologia descrita por Saint-Denis et al. (2001). Para avaliar a atividade da plasmina, amostras de leite $(1 \mathrm{~mL})$ foram pré-incubadas por 10 minutos a $37^{\circ} \mathrm{C}$ com $1 \mathrm{~mL}$ de tampão Tris- $\mathrm{HCl}$ $100 \mathrm{mM}(\mathrm{pH} 8,0)$, contendo ácido $\varepsilon$-aminocaproico 8 $\mathrm{mM}$ e $\mathrm{NaCl}$ 0,4 M, e gelatina $\left(4 \mathrm{~g} \cdot \mathrm{L}^{-1}\right)$, com objetivo de dissociar a plasmina das micelas de caseína. A atividade da plasmina foi determinada quantificando-se a concentração de 7-amido-4-metil cumarina (AMC), um produto fluorescente liberado pela plasmina a partir de um peptídeo (PIERZCHALA, 1979). A quantificação de AMC foi realizada em detector de fluorescência (Shimadzu, Japão) equipado com célula para cubetas de $1 \mathrm{~cm}$ de percurso óptico, utilizando-se excitação a $370 \mathrm{~nm}$ e emissão a $440 \mathrm{~nm}$. A curva de calibração foi preparada utilizando-se soluções padrão contendo 0,5, 1,25, 2,5 e $5,0 \mu \mathrm{g} \cdot \mathrm{mL}^{-1}$ de plasmina, preparadas de acordo com Saint-Denis et al. (2001). Os resultados foram expressos em unidades Sigma (US), considerando 1,0 US = 1,0 mM AMC liberado no ensaio.

\subsection{Determinação das frações de caseína}

As frações individuais de caseína do leite foram determinadas por meio de cromatografia líquida de alta eficiência (CLAE), seguindo rigorosamente os procedimentos descritos por Fernandes et al. (2008). A separação e a identificação preliminar das proteínas foram realizadas no sistema CLAE (Shimadzu, Japão), equipado com detector de luz UV e coluna Júpiter C18 (4 $\mu \mathrm{m}, 4,6 \times 150 \mathrm{~mm}$ ) (Phenomenex, Torrance, USA). As amostras foram filtradas através de membrana de PTFE 0,45 $\mu \mathrm{m}$ (Millipore, USA), sendo que $20 \mu \mathrm{L}$ da solução foram injetados no sistema CLAE. A corrida cromatográfica foi realizada em temperatura ambiente, nas condições preconizadas por Bobe et al. (1998), detalhadas a seguir. Fases móveis: misturas de solventes $A$ (acetonitrila + água + ácido trifluroacético - $100: 900: 1$ ) e B (acetonitrila + água + ácido trifluroacético - $900: 100: 1$ ). O programa de gradiente foi iniciado com $25 \%$ do solvente $\mathrm{B}$, aumentando-se gradativamente a proporção do solvente B imediatamente após a injeção da amostra [34\% (4 minutos), 48\% (11 minutos), 50\% (13 minutos), 10\% (17 minutos)], retornando em seguida às condições iniciais, após 2 minutos; Fluxo: 1,0 mL/minuto; Comprimento de onda do detector: $220 \mathrm{~nm}$. Nestas conduções, os tempos de retenção de $\alpha_{s 1}$-caseína, $\alpha_{s 2}$-caseína, $\beta$-caseína e -caseína foram 10,9 minutos, 9,3 minutos, 11,4 minutos e 8,3 minutos, respectivamente.

Os resultados das análises da atividade de plasmina e das frações de caseína no leite UAT aos 10, 30, 60, 90 e 120 dias de armazenamento foram utilizados para determinar o coeficiente de correlação de Pearson (r). O efeito do tempo de armazenamento em frações de caseína no leite longa vida foi determinado utilizando-se o procedimento proc mixed do $\mathrm{SAS}^{\circledR}$ (SAS, 2004). Em todos os casos, a significância foi testada no nível de probabilidade de 0,05.

\section{Resultados e discussão}

A CCS nos lotes de leite cru utilizados na fabricação do leite longa vida variou de 342.000 a 808.000 células. $\mathrm{mL}^{-1}$, ou 5,53 a 5,91 Log células. $\mathrm{mL}^{-1}$ (Figura 1). Os valores de atividade de plasmina variaram entre 172 e 184 US, sendo correlacionados com a CCS do leite cru $(r=0,9101 ; P=0,0263)$. Esses resultados corroboram os dados reportados por outros autores sobre o aumento da atividade de plasmina em leites provenientes de vacas com alta CCS (BASTIAN e BROWN, 1996).

A Tabela 1 apresenta os coeficientes de correlação entre os níveis de plasmina e as frações de caseína no leite

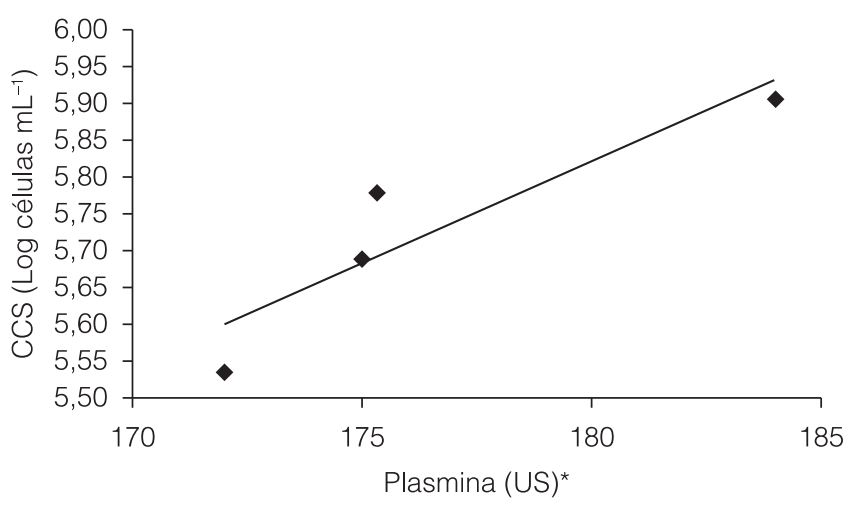

Figura 1. Contagem de células somáticas (CCS) e concentrações de plasmina nos quatro lotes de leite cru utilizado na fabricação do leite longa vida. A respectiva equação de regressão é: $y=0,0277 x+0,8358(r=0,9101 ; P=0,0263) .{ }^{*} U S=$ Unidade Sigma (1,0 US = 1,0 mM 7-amido-4-metil cumarina).

Tabela 1. Correlações entre as atividades de plasmina sobre as frações de caseína do leite UAT integral durante 120 dias de armazenamento.

\begin{tabular}{lccc}
\multicolumn{1}{c}{ Correlação } & $\mathbf{r}$ & $\mathbf{P}$ & Equação \\
Plasmina $\times \alpha_{\mathrm{s} 1}$-caseína & $-0,5074$ & 0,0224 & $\mathrm{y}=0,0422 \mathrm{x}+19,253$ \\
Plasmina $\times \alpha_{\mathrm{s} 2}$-caseína & 0,3288 & 0,1570 & - \\
Plasmina $\times \beta$-caseína & $-0,4408$ & 0,0517 & - \\
Plasmina $\times$ K-caseína & $-0,1287$ & 0,5886 & - \\
\hline
\end{tabular}


longa vida nos 120 dias de armazenamento. Constatou-se somente correlação negativa $(r=-0,5074 ; P=0,0224)$ entre a atividade de plasmina e a concentração de $\alpha_{s 1}$-caseína, sendo observada também uma tendência de correlação negativa entre plasmina e $\beta$-caseína $(r=-0,4408 ; P=0,0517)$. Estes resultados estão de acordo com os apresentados por Srinivasan e Lucey (2002), os quais constataram que a ação da plasmina degrada principalmente as frações $\alpha_{S_{1}{ }^{-}}, \alpha_{S 2}$ e $\beta$-caseína, sendo que esta atividade foi capaz de alterar as propriedades de coagulação do leite. O aumento na atividade de plasmina no leite longa vida em relação ao leite cru confirma a estabilidade térmica desta enzima, conforme observado por outros autores, em leites pasteurizados (VERDI e BARBANO, 1991; BASTIAN e BROWN, 1996).

A Figura 2 apresenta a evolução da atividade de plasmina e das concentrações de $\alpha_{s 1}$-caseína no leite longa vida durante o armazenamento por 120 dias. Observou-se que o aumento dos níveis de plasmina ao longo deste período $(r=0,9823 ; P=0,0127)$ foi acompanhado pela redução dos níveis de $\alpha_{s 1}$-caseína $(r=0,7613 ; P=0,0170)$. Esta diminuição das concentrações de caseína pode estar associada em grande parte à CCS (FERNANDES et al., 2008), o que predispõe o leite a uma substancial hidrólise da $\alpha$ - e da $\beta$-caseína por proteases, havendo diminuição nos níveis destas frações no leite (VERDI e BARBANO, 1991). De fato, Fernandes et al. (2008) observaram que a CCS foi correlacionada à redução nas concentrações de $\beta$-caseína no leite longa vida durante o armazenamento, atribuindo este fato principalmente à plasmina.

A proteólise das caseínas é variável de acordo com a origem das proteases. As proteases produzidas por microrganismos psicrotróficos causam proteólise com maior intensidade nas frações $\beta$ - e $\kappa$-, seguidas da $\alpha_{S 1}$-caseína (FERNANDES e OLIVEIRA, 2007). Entretanto,

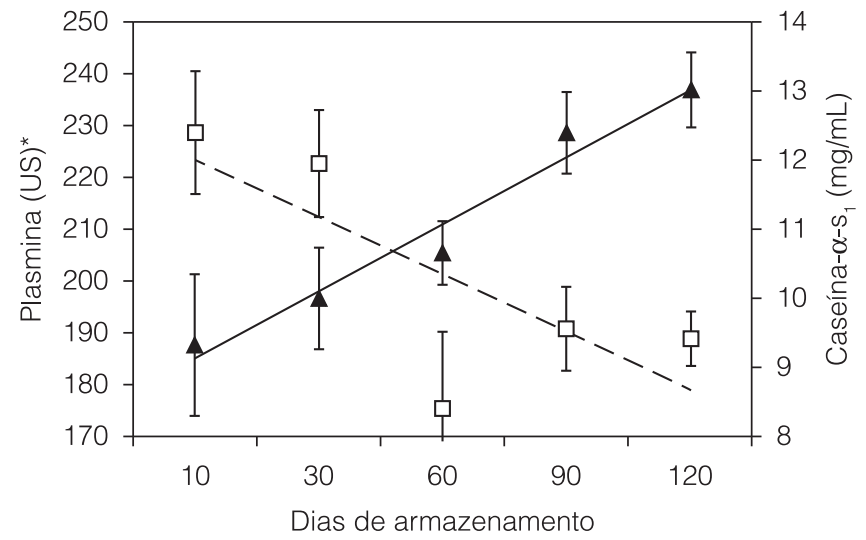

Figura 2. Concentrações de plasmina ( $\boldsymbol{\Delta}$ ) e caseína- $\alpha \mathrm{s}_{1}(\square)$ no leite longa vida durante o armazenamento por 120 dias. As respectivas equações de regressão são: plasmina: $y=13,05 x+172(r=0,9823 ; P=0,0127)$; caseína- $\alpha s_{1}$ : $y=-0,834 x+12,855(r=0,7613 ; P=0,0170) .{ }^{*} U S=$ Unidade Sigma (1,0 US = 1,0 mM 7-amido-4-metil cumarina). estas proteases parecem não causar problemas até que seja alcançado um nível de, no mínimo, 1,0 × 107 UFC. $\mathrm{mL}^{-1}$ de psicrotróficos (ARCURI et al., 2004). No presente trabalho, somente foram avaliados lotes de leite cru que apresentaram até $1,0 \times 10^{4}$ UFC. $\mathrm{mL}^{-1}$ para mesófilos e $1,0 \times 10^{3}$ UFC. $\mathrm{mL}^{-1}$ para psicrotróficos. Deste modo, a diminuição dos níveis de $\alpha_{\mathrm{s} 1}$-caseína observada durante o armazenamento do leite longa vida pode ser atribuída à ação proteolítica da plasmina, cuja atividade foi correlacionada à variação da CCS no leite cru utilizado como matéria-prima.

Durante o período de armazenamento do leite longa vida, não foram constatadas, por simples observação visual, alterações de cor ou aspecto nas amostras analisadas. No entanto, a consequência provável e de maior importância das mudanças nas frações de caseína no leite longa vida é a desagregação das micelas de caseína, uma vez que este fenômeno está envolvido em diversas alterações indesejáveis no leite, sobretudo a gelificação durante a vida de prateleira do produto (DATTA e DEETH, 2001).

\section{Conclusões}

A atividade de plasmina no leite cru foi proporcionalmente maior nos leites com maior CCS, cujos valores aumentaram durante o armazenamento do leite longa vida por 120 dias à temperatura ambiente. Durante esse período, o aumento da atividade de plasmina foi acompanhado de redução das concentrações de $\alpha_{\mathrm{s} 1}$-caseína no leite longa vida.

\section{Agradecimentos}

Os autores agradecem ao Conselho Nacional de Desenvolvimento Científico e Tecnológico (CNPq), pelo suporte financeiro (processo n. ${ }^{\circ}$ 152616/2007-1).

\section{Referências}

ASSOCIAÇÃO BRASILEIRA DE LEITE LONGA VIDA - ABLV. Estatísticas do Leite Longa Vida no Brasil. São Paulo: ABLV, 2009. Disponível em: <http://www.ablv.org.br/Estatisticas. aspx>. Acesso em: 15 mar. 2011.

AMERICAN PUBLIC HEALTH ASSOCIATION - APHA. Standard Methods for the Examination of Dairy Products. 17th ed. Washington: APHA, 2004. 570 p.

ARCURI, E. F.; TAVARES, W. P. P.; PEREIRA, D. B. C.; BRITO, M. A. V. P. Efeito do crescimento de Pseudomonas sp. proteolítica na estabilidade do leite ao etanol. Revista do Instituto de Laticínios "Cândido Tostes", Juiz de Fora, v. 59, n. 339, p. 140-144, 2004.

BASTIAN, E. D.; BROWN, R. J. Plasmin in milk and dairy products: an update. International Dairy Journal, Edmonton, 
Relação entre atividade de plasmina e frações de caseína durante o armazenamento do leite longa vida CORASSIN, C. H. et al.

v. 6, n. 5, p. 435-57, 1996. http://dx.doi.org/10.1016/09586946(95)00021-6

BOBE, G.; BEITZ, D. C.; FREEMAN, A. E.; LINDBERG, G. L. Separation and quantification of bovine milk proteins by reversed phase high performance liquid chromatography. Journal of Agricultural and Food Chemistry, Washington, v. 46, n. 2, p. 458-463, 1998. http://dx.doi.org/10.1021/jf970499p

DATTA, N.; DEETH, H. C. Age gelation of UHT milk - a review. Food and Bioproducts Processing, London, v. 79, n. 4, p. 197-210, 2001. http://dx.doi.org/10.1205/096030801753252261 FERNANDES, A. M.; OLIVEIRA, C. A. F. Atividade enzimática relacionada às células somáticas no leite. Revista do Instituto de Laticínios "Cândido Tostes”, Juiz de Fora, v. 62, n. 356, p. 17-25, 2007.

FERNANDES, A. M.; BOVO, F.; MORRETI, T. S.; ROSIM, R. E.; LIMA, C. G.; OLIVEIRA, C. A. F. Casein fractions of ultra high temperature milk with different somatic cell counts. Pesquisa Agropecuária Brasileira, Brasília, v. 43, n. 1, p. 149-152, 2008. http://dx.doi.org/10.1590/S0100-204X2008000100019

ISMAIL, B.; NIELSEN, S. S. Invited review: Plasmin protease in milk: Current knowledge and relevance to dairy industry. Journal of Dairy Science, Urbana, v. 93, n. 11, p. 4999-5009, 2010. http://dx.doi.org/10.3168/jds.2010-3122

KOHLMANN, K. L.; NIELSEN, S. S.; LADISCH, M. R. Effect of serine proteolytic enzymes (trypsin and plasmin), trypsin inhibitor, and plasminogen activator addition to ultra high temperature processed milk. Journal of Dairy Science, Urbana, v. 71 , n. 7 , p. 1728-1739, 1988. http://dx.doi.org/10.3168/jds. S0022-0302(88)79739-8

LÜCK, H. Control de la calidad de la industria lactologica. In: ROBINSON, R. K. (Ed.). Microbiologia Lactologica. Zaragoza: Acribia, 1987. v. 2, p. 255-94.

METWALLI, A. A. M.; JONGH, H. H. J.; VAN BOEKEL, M. A. J. S. Heat inactivation of bovine plasmin. International Dairy Journal, Edmonton, v. 8, p. 47-56, 1998. http://dx.doi.org/10.1016/S0958$69469800017 X$

PIERZCHALA, P. A. A new fluorogenic substrate for plasmin. Biochemistry Journal, Portland, v. 183, n. 3, p. 555-559, 1979.

SAINT-DENIS, T.; HUMBERT, G.; GAILLARD, J. L. Enzymatic assays for native plasmin, plasminogen and plasminogen activators in bovine milk. Journal of Dairy Research, Cambridge, v. 68, n. 3, p. 437-449, 2001. http://dx.doi. org/10.1017/S0022029901004939

STATISTICAL ANALISYS SYSTEM INSTITUTE - SAS. SAS User's Guide: Statistics. Cary: SAS Institute Inc., 2004. 441 p.

SRINIVASAN, M.; LUCEY, J. A. Effects of added plasmin on the formation and rheological properties of rennet-induced skim milk gels. Journal of Dairy Science, Urbana, v. 85, n. 5, p. 1070-1078, 2002. http://dx.doi.org/10.3168/jds.S00220302(02)74167-2

VERDI, R. J.; BARBANO, D. M. Effect of coagulants, somatic cell enzymes, and extracellular bacterial enzymes on plasminogen activation. Journal of Dairy Science, Urbana, v. 74, n. 3, p. 772-782, 1991. http://dx.doi.org/10.3168/jds. s0022-0302(91)78224-6 